\title{
Repensando o rádio na era digital
}

/////////////////// Andrew Dubber ${ }^{1}$

1. Professor na área de inovação nas indústrias da musica (music industries innovation) na Universidade da Cidade de Birmingham (Birmingham City University). E-mail: dubber@gmail.com 


\section{Resumo}

O rádio vem, há muito tempo, sendo considerado como um meio de comunicação com especificidade tecnológica, institucional e comunicativa. No entanto, tendo em vista o surgimento de um ambiente midiático caracterizado pelas tecnologias digitais, fazse necessário não só investigar o que aconteceu com o rádio, mas mesmo reavaliar também nossa compreensão sobre o que ele sempre foi. Este artigo defende uma abordagem para o estudo do rádio através da ecologia midiática, que possa reconhecer a periodização da história dos meios e possa considerar a forma e o discurso do rádio como uma negociação entre potencialidades e efetividades.

Palavras-chave

Rádio, tecnologias digitais, ecologia midiática.

Abstract

Radio has long been considered and studied as a particular technological, institutional and communicative form. However, as a result of the emergence of a media environment characterised by digital technologies, it has become necessary to examine not only what has happened to radio, but also to re-evaluate our understanding of what it was in the first place. This article argues for a media ecology approach to an understanding of radio; one that acknowledges a periodisation of media history, and which considers the form and discourse of radio as a negotiation of affordances and effectivities.

\section{Keywords}

Radio, digital technologies, media ecology. 
2. Termo original: dumpling, um tipo de bolinho ou trouxa feito de massa.
Nas últimas duas décadas, foram escritos uma grande quantidade de artigos científicos e publicadas uma série de reflexões na impressa popular e comercial sobre o que teria acontecido ou não com o meio radiofônico como efeito do desenvolvimento e da ampla adoção das mídias digitais. Esses textos parecem adotar um entendimento comum do que o rádio era e assim propõem que, para entender as mudanças ocorridas, é necessário tão somente observar a natureza e o impacto das diferenças tecnológicas e, desse modo, descrevem a forma do rádio alterada em suas características essenciais como resultado desse impacto. Na verdade, "impacto" é uma das palavras mais usadas e, como vou argumentar aqui, também uma das menos apropriadas para descrever o efeito das tecnologias digitais sobre o que chamamos de rádio. Dizer que "impacto" é menos apropriado pode levar o leitor a pensar que um objeto externo incidiu sobre a superfície de uma entidade fixa e que, dessa forma, ele mudou sua forma. Em outras palavras, se a tecnologia digital teve um "impacto" sobre o rádio, então ela necessariamente deixou uma marca nesse meio, ou quem sabe ela até mesmo o tenha danificado sem possibilidade de conserto. Mas, tomado como uma metáfora para o que realmente aconteceu com o rádio, o conceito de "impacto" é inadequado. A mudança foi, melhor dizendo, de contexto. Como um ravióli ${ }^{2}$ tirado de uma sopa específica e levado para outra, o rádio foi totalmente recontextualizado; seu potencial, significado e "sabor" foram alterados.

$\mathrm{Na}$ verdade, a recontextualização do rádio dentro de um ambiente de mídia digital reforça o fato de que já, há muito 
3. Para entender o rádio. Sem edição em português.

4. Termo original utilizado com perspectiva mais abrangente: radiodrama. tempo, existe um duplo problema derivado do essencialismo e do determinismo que prejudicam o pensar sobre rádio, e ambos têm se espalhado na literatura dos estudos de rádio há tempos. Tanto pesquisadores acadêmicos quanto profissionais do rádio vêm atribuindo certas características (ou, melhor dizendo, com menos peso, "tendências") à mídia que são na verdade pertinentes às bases da era eletrônica dentro da qual o rádio foi situado.

Por exemplo, logo no início do livro Understanding radio 3 , Andrew Crisell (1986) afirma: "O que chama a atenção de todos, tanto locutores quanto ouvintes, como algo significativo sobre o rádio é que ele é uma mídia cega". Desde a publicação do referido livro, os conceitos de cegueira e invisibilidade têm sido apropriados por outros pesquisadores (por exemplo, por SHINGLER; WIERINGA, 1998, p. 74; BECK, 1999; LACEY, 2009). No entanto, aparentemente, ignorou-se por completo a expressão totalizante e problemática "o que chama a atenção de todos". Independentemente de qual seja o adjetivo certo que Crisell esteja buscando, a implicação mais importante do que ele diz aqui é que se trata de uma característica experimentada universalmente e inerente ao meio. Eu defendo que nenhuma dessas duas coisas é verdadeira.

Definições são sempre problemáticas, é claro, e tentar determinar exatamente quais são os limites do rádio é, por isso, uma empreitada árdua, senão impossível. E, por mais que possamos concordar em princípio (ou ao menos na prática) que o rádio possa ser, por exemplo, uma mídia secundária ou uma mídia pessoal, é fácil encontrar bons contraexemplos para cada uma dessas proposições. Mais ainda: fica sempre mal explicado ou subentendido que todos sabemos aquilo a que se está referindo quando fala-se de rádio. Mas a própria palavra pode referir-se a uma instituição; a um método de transmissão; a uma série de práticas profissionais; a ondas num espectro eletromagnético; a um aparelho concreto que fica no banco da cozinha ou instalado no painel de um carro; ou ele pode ser ainda um tipo de programa, quando se quer distingui-lo de outros da mesma família (radionovela ${ }^{4}$, radiodocumentário, rádio comercial etc.). 
O rádio se relaciona com políticas econômicas, com a legislação, com uma ampla gama de tecnologias, com as propriedades físicas da radiação no espectro eletromagnético (e com nossa habilidade para utilizar esses tipos de onda), com promoções, com a integração da indústria da música, com manifestações no nível local, regional e também nacional, com marcas, com celebridades, com a vida de pessoas reais (tanto o público e os entrevistados como aqueles que trabalham no rádio) e - muito importante - com outras mídias. Ele é diferente em cada lugar, em cada tempo e em diferentes contextos. Mais ainda, na maioria das vezes ele é diferente quando passamos de uma instância a outra até dentro da mesma localização geográfica, do mesmo quadro legal, do mesmo clima político e período histórico. O que o rádio é, falando ontologicamente, pode variar se passarmos de uma posição a outra no dial ou de um aparelho a outro dentro da mesma casa. Dizer "O rádio é..." qualquer coisa de essencial sugere uma visão do meio que é particularmente rasa, geocentrada, tecnologicamente determinante e altamente limitada. É claro que isso gera problemas para a discussão da natureza mutante do rádio. Sem uma concordância ou sem uma noção estabelecida de um estado precedente, analisar a incidência de uma ecologia transformada é praticamente impossível de maneira prática.

$\mathrm{E}$, ainda assim, mais do que qualquer característica que seja intrínseca ao meio em si, o que impressiona este autor em relação ao rádio é a conexão que ele estabelece com a vida das pessoas, com sua história, com o desenvolvimento tecnológico, com trabalhos feitos na indústria, com a programação: drama; música; documentário; revista; comentário; notícia; entretenimento e outros gêneros - com a cultura popular e com um entendimento comum sobre nossa sociedade e como ela funciona. Importante notar, ainda, que essas coisas - todas elas - mudam com o tempo em resposta às transformações ambientais, culturais, tecnológicas, legislativas e sociais. Mas nenhuma delas é essencial ao rádio. O rádio pode existir sem música. Ele pode existir dentro de um quadro legal completamente diferente. Ele existe independentemente do uso de ondas de rádio. Ele pode existir fora do contexto das marcas e das estações. Ele não precisar ser nem pessoal nem secundário. Essa pode ser a convenção, mas certamente não são características necessárias para o que chamamos de "rádio". 
5. Consumer Expert Group (grupo especialista em consumo), associação britânica dedicada aos direitos do consumidor.

6. Digital audio broadcasting (transmissão digital de áudio).

7. Grifo nosso.
Os ouvintes têm muito a ver com isso. A identidade de um meio emana em parte de como ele é recebido e tratado por seus usuários. Claro que os ouvintes podem ser provocados de uma maneira ou de outra pela indústria. Mas, se por qualquer motivo o áudio na internet for tratado como se fosse rádio, então até certo ponto irredutível trata-se de rádio.
A análise feita por David Black (2001) sobre o rádio na internet encontra esse problema, e o autor chega à conclusão provavelmente inevitável de que o rádio melhor se define simplesmente como sendo aquilo que as pessoas concordam em chamar de rádio:

De uma perspectiva puramente pragmática, o problema da medição também surge nesse ambiente em transformação. Definições parecem ser necessárias simplesmente porque o mercado do rádio demanda que os ouvintes sejam contados. Para que essa atividade seja relevante, limites precisam ser estabelecidos. Decisões precisam ser tomadas em relação ao que, no contexto digital, pode ou não ser considerado rádio. Stephen Lax (2011) enfatiza essa questão em seu exame sobre o rádio digital na Grã-Bretanha.

[o $\left.\mathrm{CEG}^{5}\right]$ indica que "ouvir no meio digital" nesse sentido deveria significar ouvir o rádio $\mathrm{DAB}^{6}$, mais do que envolver todas as plataformas digitais. Isso possibilitaria comparar coisas iguais, já que o DAB, um sistema de transmissão físico, substituiu diretamente o rádio FM. Assim como o FM, então, ele era portátil, ao passo que ouvir rádio através da televisão ou da internet era uma experiência diferente que não incorporava a essência do rádio ${ }^{7}$, sua mobilidade. Uma pesquisa realizada para a BBC Trust defende a importância da portabilidade do rádio como sendo uma característica definidora do meio.

É palpável, nesse texto, a pura arbitrariedade da definição de que para ser considerado rádio algo precisa ser primeiro "portátil", mas a necessidade de traçar os limites de um meio com o objetivo de obter estatísticas úteis para a condução dos negócios e para informar a realização de políticas relaciona-se à compulsão de 
insistir que o meio tenha qualquer essência característica, seja portabilidade, seja "secundidade", seja transmissão através do espectro seja, até mesmo, cegueira.

Eu não posso concordar (na verdade, eu considero bem absurdo) que um aparelho, para ser considerado "rádio", deva ter a qualidade da portabilidade. E isso não ajuda a pensar se podemos ou não considerar o podcast como parte da família de conteúdos midiáticos radiofônicos - nem a pensar se é relevante o fato de a programação ser desenvolvida por profissionais dentro de uma instituição de radiodifusão.

Como estudiosos do rádio, é importante que haja um entendimento comum do que queremos dizer quando falamos "rádio", aceitando as limitações impostas pela flexibilidade e dependência do contexto que essa terminologia implica. Se o rádio é, como Black sugeria acima, o que as pessoas dizem que ele é, então o rádio pode ser praticamente qualquer coisa no nível teórico. Esse parece um problema ainda pior do que o essencialismo total. Então minha posição é a de que, de outro modo, o rádio é sim alguma coisa específica, mas sua especificidade deve ser identificada pelo exame do que é consistente nas práticas discursivas dinâmicas que o circundam, mais do que pelo apontar de algumas características essenciais, de um lado, ou pela autorização de qualquer interpretação como aceitável, de outro. Proponho que o rádio não tem exatamente nenhuma característica essencial - nem mesmo que favoreça o áudio frente à comunicação visual. E, ainda que a maior parte dos formatos radiofônicos encontrados tenham o caráter de mídia preferencialmente sonora, há outros formatos de mídia comunicacional que não chamamos de rádio e que também priorizam o conteúdo sonoro (CDs, iPods, telefones, campainhas com funcionamento remoto, fones Bluetooth...). Então, em vez de procurar características que persistam para além dos formatos de rádio, do período histórico, da geografia, do propósito ou do contexto, sugiro a existência de categorias que possamos usar para falar de rádio e que recortem todos esses diferentes ambientes. Esses quadros categóricos continuam a ser úteis mesmo com as mudanças que possam acontecer em qualquer aspecto do rádio. 
8. Rádio na era digital, sem edição em português.
9. Por exemplo, pode-se concentrar na questão do aparelho uma análise da recepção, da interferência, da comparação entre especificações técnicas e das discussões sobre a forma de incorporação à vida diária (como portabilidade ou posição ocupada na casa).
Em meu livro Radio in the digital age ${ }^{8}$ (2013), proponho uma série de categorias discursivas, mais que uma definição fixa do rádio. Independentemente dos contextos sociais e políticos em que falamos sobre o rádio, há certos tipos de diálogo que temos que poderiam ser considerados "diálogos sobre rádio", embora abandonemos a conceituação fixa do que o rádio pode ser em si. Listo abaixo as categorias mencionadas como aparecem no livro.

\section{Dispositivo}

Há uma forma física tangível - uma máquina, se preferirmos - que podemos chamar de "rádio". Ele pode ser encontrado na cozinha, no painel do carro, pode ser parte do sistema estéreo de uma casa, pode ser integrado (ou incluído como um software) em telefones celulares e laptops, e assim por diante. A manifestação física do aparelho de rádio é importante não só por ser onde ouvimos rádio, mas, sob vários aspectos, ele mesmo é a coisa que estamos ouvindo. Focar no aparelho de rádio faz a nossa atenção voltar-se para as propriedades e características do meio ${ }^{9}$ pelo qual a própria experiência de rádio acontece.

\section{Transmissão}

Seja via onda eletromagnética de rádio com diferentes comprimentos de onda, modulados pela amplitude ou frequência, seja via internet cabeada, comunicação por celular, satélite ou algum outro método de difusão, as maneiras pelas quais o conteúdo radiofônico chega aos aparelhos é um item importante numa discussão que se pretenda completa sobre o rádio. As transformações nos modos de transmissão afetam todas as outras categorias do discurso radiofônico listadas aqui - e são afetadas por elas.

\section{Texto}

Falamos de textos para o rádio, que podem ser a programação, é claro - mas, como categoria discursiva, eles também incluem todos os formatos variados, shows, publicidades, dramas, documentários, podcasts, locuções, listas de reprodução (playlists), músicas e assim por diante. 


\section{Subtexto}

São os significados e as intenções dos textos - incluindo os propósitos envolvidos no fazer radiofônico (por exemplo, os valores reithianos, as empreitadas comerciais) - que modelam a maneira como o rádio se manifesta. Podemos também relacionar os subtextos do rádio como metanarrativas ${ }^{10}$.

\section{Sem dúvida, a passagem de uma} "era midiática" a outra no rádio é uma dessas metanarrativas.

\section{Público}

Sendo um termo problemático (especialmente no ambiente digital, em que o limite entre o produtor e o consumidor é frequentemente borrado), muito do discurso do rádio envolve as pessoas que "consomem" o texto - sejam cocriadores e participantes da construção do texto, sejam apenas receptores passivos - em grupo ou individualmente.

\section{Estação}

Embora a ideia de "estação" possa imprimir um tipo específico de prática profissional e modelo institucional no discurso do rádio, pretendemos usar o termo de maneira mais ampla para fazer referência ao quadro organizacional em cujo contexto os textos para o rádio são germinados e produzidos.

\section{Política econômica}

É importante levar em consideração o ambiente legislativo, a configuração política e as forças econômicas que conformam o meio e, igualmente, as formas pelas quais o rádio gera capital ou engaja alguma função social ou cívica.

\section{Produção tecnológica}

São as ferramentas utilizadas para criar os textos para rádio. A produção tecnológica pode envolver microfones, mesas de mixagem, equipamentos com fita ou, na verdade, smartphones em que programas e segmentos da programação são produzidos. 


\section{Prática profissional}

Essa categoria discursiva se relaciona de perto com a produção tecnológica e na maioria das vezes se refere à operação da tecnologia por aqueles que são o "trabalho do rádio", seja por emprego, seja por hobby, seja por engajamento voluntário. No entanto, muitas das práticas envolvidas no fazer radiofônico podem não necessariamente estar relacionadas ao uso das produções tecnológicas pelo rádio (por exemplo, vendas no rádio).

\section{Cultura promocional}

Essa categoria lida com as formas pelas quais o rádio contribui para outras atividades, produtos e serviços, e se relaciona com eles. Isso envolve a integração do negócio da música, anúncios relativos aos serviços públicos, entrevistas com autores e assim por diante. A cultura promocional do rádio está inevitavelmente ligada aos textos e subtextos do rádio, mas exige um quadro analítico independente que direcione a atenção para o efeito (pretendido) no comportamento de consumo do público.

Essas dez categorias ou quadros discursivos oferecem caminhos pelos quais uma análise do rádio pode ser realizada. E, embora as questões discutidas dentro de cada quadro estejam sujeitas a mudanças radicais em diferentes lugares, tempos, contextos e ambientes tecnológicos, essas categorias persistem. Numa cidade, num ponto da história, diferentes manifestações do rádio podem coexistir sem que nenhuma delas compartilhe características presentes dentro de qualquer uma das categorias e ainda assim podem ser igualmente consideradas rádio. Ainda que seja óbvio que nem tudo seja rádio, também não há uma característica ou conjunto de parâmetros compartilhado por todas as manifestações de rádio que possa identificá-las como pertencendo ao terreno discursivo chamado coletivamente de "rádio". O propósito das dez categorias listadas acima é, dessa forma, o de oferecer um quadro a partir do qual podemos articular um debate sobre as mudanças no rádio. Em outras palavras, o rádio sempre foi multifacetado, complexo e diversificado. Mas atualmente ele assumiu ainda novas formas variadas do multifacetado, complexo e diverso. 
11. Certamente, formas análogas que dependiam das tecnologias iniciais

da "era eletrônica" continuam persistindo, embora seu significado

tenha se alterado durante sua recontextualização numa era digital.

\section{Periodização da história midiática}

Agora que temos uma série de categorias com as quais explorar e compreender o rádio (ainda que sem poder fixar definições marcadas em cima delas), estamos prontos para abordá-lo como um objeto fenomenológico e ontológico de análise dentro de uma gama de contextos midiáticos diferentes. Se aceitarmos que o rádio é uma prática discursiva complexa per se e que está enquadrada dentro de uma perspectiva política, geográfica e cultural, é razoável concordar também que o rádio na era digital é necessariamente tão complexo e multifacetado como na era "prédigital". A diferença reside em grande parte no fato de que ele se contextualiza dentro de um ambiente tecnológico caracterizado por formatos digitais de mídia e por metodologias comunicacionais. Falar do rádio na era digital é assumir que digital é a era, mais do que entender a digitalização como algo que "aconteceu” com o rádio ${ }^{11}$. Tirar a ênfase do objeto e colocá-la no contexto possibilita uma ampla e variada percepção de complexidades, continuidades e descontinuidades. A maior parte das análises feitas sobre o rádio na era digital têm sido focadas especificamente na digitalização dos métodos de transmissão ou na digitalização do conteúdo transmitido (por exemplo, LAX, 2011; O’NEILL, 2008; RUDIN, 2006; DUNAWAY, 2000; BLACK, 2001; INSKIP, 2009 etc.); ou têm sido centradas na aplicação do que se pensa tradicionalmente como programação "radiofônica” e de suas produções técnicas para os formatos de mídia digital que não são sempre considerados como "rádio" no senso convencional (ver BERRY, 2006).

Mudar o foco do meio comunicacional para seu ambiente requer a periodização de sua história, dividindo em duas eras midiáticas diferentes. Nesse sentido, a era digital pode ser entendida como um período discreto na história das mídias, numa perspectiva tanto cultural quanto tecnológica. Algumas ideias desenvolvidas no campo da ecologia midiática ajudam a entender a noção de digitalização e o efeito que esse ambiente transformado tem sobre a mídia que utilizamos. Nesse ponto, também me valho do conceito de "potencialidades"12" vindo da psicologia (GIBSON, 1977), e particularmente de seu uso dentro de um quadro ontológico 
13. Por exemplo, uma das convenções-padrão para a mídia eletrônica (mais do que uma de suas características indispensáveis - e essa é uma distinção importante)

é que sua comunicação seja estruturada numa arquitetura tipo um-para-muitos-como-grupo (em oposição à da era da impressão, tipo um-para-muitos-indivíduos). Isso, sem dúvida, tem muita relação com o caráter das instituições políticas e culturais do século XX, assim como tem relação com o desenvolvimento e implementação de tecnologias, mas é certamente um tema recorrente no formato de mídia da era eletrônica.
(SANDERS, 1997), oferecendo uma maneira pela qual os ambientes (especificamente, de acordo com nosso propósito, os ambientes midiáticos) podem ser entendidos como espaços em que algumas oportunidades estão disponíveis para um ator inserido neles. Conforme o ambiente muda (de um contexto analógico para um digital), também se alteram as potencialidades e, assim, oportunidades diferentes tornam-se disponíveis, enquanto outras ficam menos acessíveis.

Proponho que o "rádio" contemporâneo é digital praticamente da mesma maneira que o rádio do século XX era "eletrônico". Ou seja, ele não apenas usou aquele "toque" particular de tecnologia mas também seguiu convenções e práticas inscritas no ambiente midiático em que a referida prática discursiva aconteceu ${ }^{13}$. Falar de uma era define e historiciza um período que é caracterizado por um aspecto prevalente da mesma era - especificamente, eu diria que um aspecto tecnológico ou midiático nela prevalente. Creditase a Hesíodo a tentativa de dividir a história em eras metálicas (bronze e ferro inclusos, bem como as hipotéticas era da prata e era do ouro). Seguindo a classificação de C. J. Thomsen para achados arqueológicos, baseada na tipologia e na cronologia dos objetos encontrados, arqueólogos e paleoantropólogos utilizam atualmente um "Sistema de Três Idades" (Idade da Pedra, Idade do Bronze e Idade do Ferro) para apresentar as fases do desenvolvimento intelectual e cultural humano fundamentado na primazia das tecnologias, das matérias-primas e ferramentas usadas para a criação dos artefatos culturais de uma determinada sociedade (ver: MALINA; VAŠÍCEK, 1990; BARHAM; MITCHELL, 2008; LUBBOCK, 1865; GRÄSLUND, 1987; HEIZER, 1962). Essas idades são ainda subdivididas: a Idade da Pedra, em paleolítico, mesolítico e neolítico; a Idade do Bronze, em cobre e bronze. Elas descrevem não apenas aspectos das atividades e dos objetos relacionados às pessoas que viveram nesses períodos mas também os tipos de economia, de estrutura social, de infraestrutura política e religiosa deles. Isso significa dizer que o meio de comunicação principal de uma era apresentava o contexto em que emergiram 
14. Técnicas e civilização, sem edição em português.

15. Para McLuhan, todas as tecnologias são comunicativas e, assim, o autor classifica qualquer

ferramenta ou invenção como uma mídia. Dessa forma, a era da pedra foi um período em que se pode dizer que os seres humanos se comunicavam preferencialmente pela mídia pedra. No entanto, para McLuhan, embora a pedra fosse claramente importante, um desenvolvimento e uma invenção

humana mais relevantes nesse período era a mídia da fala. a natureza única, as instituições e quadro conceitual humanos do período. Em outras palavras, a civilização humana é o texto dessa mediação. Assim como Paul D. Miller sugestivamente coloca:

\footnotetext{
Pare. Pense nisso. Todas as sensações que você tem vêm de uma fonte: a civilização. Quando você terminar de ler este parágrafo, deixe o livro um pouco de lado e dê uma olhada à sua volta - observe os arredores. O que você vê, ouve, cheira, saboreia que não é originado ou mediado por pessoas civilizadas? (MILLER, 2008)
}

A ideia de civilização como sendo um contexto de mediação tem sido articulada por diversos pesquisadores ao longo do tempo, mas talvez de maneira mais notável por Lewis Mumford, em cujo trabalho Technics and civilisation ${ }^{14}$ (1934) a tecnologia é marcada ao mesmo tempo como definidora das características prevalentes da cultura de um determinado período, e especialmente da sofisticação e do desenvolvimento intelectual e prático de uma era - e sendo definida por eles. Fazendo eco da categorização de Thomsen para os períodos pré-históricos, Mumford divide a história da civilização desde a Idade Média em Idades Eotécnica, Paleotécnica e Neotécnica.

Da mesma forma (e devendo enormemente a Mumford), McLuhan (1962) demarca uma quantidade de diferentes períodos da história cultural a partir das formas dominantes de mídia e de comunicação ${ }^{15}$. No entanto, ao fazer isso, em vez de privilegiar a forma predominante de comunicação como a característica central para definir uma era da civilização, o autor deixa a arqueologia para trás e abandona as matérias-primas em estado bruto (pedra, ferro, bronze) a partir das quais culturas passadas foram erigidas. McLuhan nos oferece a fala e a escrita como duas das idades iniciais da humanidade dignas de relevância. Como uma espécie, ele afirma que tivemos uma Idade Oral, seguida de uma Idade Escrita. O meio discursivo define a civilização e o período histórico em que vivemos. Embora as coisas que fazemos com ferro ou pedra possam muito bem ser expressões de nós mesmos e de nossa cultura, nada define o que somos e pode nos expressar melhor do que o método 
16. Obra publicada em português com o título de A galáxia de Gutenberg: a formação do homem tipográfico. Tradução de Leônidas Gontijo de Carvalho e Anísio Teixeira. São Paulo: Editora Nacional, Editora da USP, 1972. primário pelo qual nos comunicamos com nossos contemporâneos (mais do que com futuros arqueólogos). Em The Gutenberg galaxy $y^{16}$ (1962), McLuhan relaciona a interiorização de uma nova tecnologia com a tradução da cultura de uma forma a outra.

Ainda, a tradução de uma cultura não é simplesmente uma mudança no que fazemos e produzimos como espécie, mas (literalmente) o que somos como espécie. A fala e a escrita são tecnologias de comunicação e como tal elas são extensão de nós mesmos. A adoção de um novo quadro tecnológico midiático interfere no equilíbrio dos nossos sentidos: os meios pelos quais absorvemos informações sobre o mundo e compomos um entendimento sobre ele. Ao mudar a natureza de nossas tecnologias, mudamos a nossa própria natureza.

\footnotetext{
Minha sugestão é a de que a ecologia da cultura tem uma base razoavelmente sólida no sensorium humano e que qualquer extensão dele como resultado de ampliação tecnológica gera um efeito valorizado de estabelecer novos equilíbrios e proporções entre os sentidos. Sendo as línguas humanas essa forma de tecnologia constituída pela expansão ou expressão (exteriorizada) de todos os sentidos de uma vez só, elas estão, de pronto, sujeitas ao impacto ou intrusão de qualquer sentido estendido mecanicamente (McLUHAN, 1962, p. 35).
}

Dessa forma, McLuhan não apenas coloca a mídia como um ambiente por natureza, mas vai mais longe, afirmando que ela é, para nós, essencialmente o único ambiente que realmente importa, por seu profundo impacto sobre o que podemos dizer, sobre como compreendemos e sobre as maneiras como percebemos (ver o argumento de Miller acima). Embora uma leitura muito literal dessa conclusão poderia levar a pensar que se trata de uma forte e problemática narrativa determinista, em que a tecnologia guia a história e em que as mídias são alguma coisa que "aconteceu conosco", na verdade, seria conveniente não ignorar a primeira parte do famoso epíteto de McLuhan: "Damos forma a nossas ferramentas e então elas, por sua vez, nos moldam”. Ou seja: nós damos forma a nossas ferramentas. 
Ala-Fossi e Stavitsky (2003, p. 28) nos fazem lembrar a provocação feita por Jock Given (1998) de que as tecnologias da comunicação digital "não são inventadas em laboratórios ou em quintais, retiradas de processos sociais, econômicos e políticos, como o determinismo tecnológico puro gostaria que acreditássemos". Mas essas ferramentas não são neutras. Na verdade, as tecnologias dominantes de nossa época (impressa, eletrônica, digital) definem nossa era de maneira tão relevante como a pedra, o bronze e o ferro fizeram pelas eras que nos precederam. E, considerando-se esse fato, nós definitivamente passamos de um período caracterizado por tecnologias eletrônicas e eletromagnéticas (gravações e transmissões, na maioria dos casos) para uma era caracterizada pelas tecnologias digitais. Ao fazer isso, mudamos de uma era de abundante mídia massiva - embora houvesse a finitude e a escassez (como a questão da disponibilidade de espectro) - para uma em que descobrimos como inserir formatos midiáticos ainda mais abundantes e replicáveis, usando-os a serviço da arte, da cultura e das ciências - e, mais simplesmente, para nos expressarmos para outros serem humanos.

As tecnologias comunicacionais não são simplesmente ferramentas externas a nós (ou forças às quais devemos resistir, que devemos dominar ou com que devemos ficar maravilhados), mas elas são na verdade, como McLuhan colocaria, extensões de nós mesmos. As mídias digitais não são algo que "acontece conosco" e transforma a comunicação - é como nos comunicamos ou, mais precisamente, somos nós, comunicando. Assim, é importante entender o que é possível ou não nesse ambiente. Se as mídias digitais são extensões de nós, e não uma força externa com a qual temos de lidar, ficamos então em posição de decidir de que maneiras usamos essas mídias para nos expressarmos. Tendo dito isso, o fato de que somos ativos não significa que temos autonomia completa. Assim como em qualquer ambiente, há regras que nos indicam o que é possível, que comportamentos são encorajados (na verdade, pode parecer que isso ocorra naturalmente) e quais ações não são compatíveis com o espaço dado (ou que ações carregam consigo certos riscos ou podem ter resultados indesejáveis). Isso significa dizer que a mídia que criamos tem "potencialidade". 
17. Efetividades, no original effectivities, conceito utilizado por J. T. Sanders e que se relaciona com seu par affordances, possibilidades.

18. É é claro que é mais complexo do que o exposto, já que novas tecnologias, como as regulações e as leis (as "tecnologias do controle" de Foucault), podem restringir uma pessoa de subir na mesa para dançar independentemente da potencialidade existente com a tecnologia da mesa. Diferentes ambientes têm potencialidades e restrições que competem entre si e que são negociadas e sujeitas a relações de poder.
Uma abordagem ontológica sobre essas "potencialidades" das mídias digitais (SANDERS, 1997) e ao mesmo tempo de nossas próprias "efetividades ${ }^{17 "}$ nos oferece uma "hipótese global" inicial (mais do que um "paradigma” - para essa diferença apontada aqui, ver CUTTING, 1982) que direciona minha visão sobre o que é possível - ou seja, que oportunidades e riscos existem - dentro do ambiente midiático das tecnologias digitais. No entanto, os níveis de subjetividade e objetividade na percepção dentro do ambiente midiático estão relativisticamente restritos pelos parâmetros do próprio ambiente (assim como Einstein indicava que o movimento poderia ser medido e observado, mas apenas relativisticamente), e, dessa forma, nossa habilidade para observar e pensar como o contexto tecnológico oferece potencialidades fica comprometida (ou pelo menos é influenciada) pela nossa imersão nele. Mas é quando o ambiente muda que nós temos a oportunidade de examinar, através de uma perspectiva "real" (ou pelo menos diferentemente relativística), a natureza e o caráter dessas potencialidades. Esse é o lugar em que nos encontramos agora.

Como uma "oportunidade para ação num ambiente" (SANDERS, 1997, p. 103), uma potencialidade é a possibilidade que subsiste dentro de um contexto compartilhado e que pode ser selecionada e articulada e basear uma ação. Por exemplo, se há uma mesa numa sala, uma potencialidade nesse ambiente seria dançar em cima da mesa. Se a sala não tivesse uma mesa, não haveria como dançar em cima dela. No entanto, deve ficar claro que mesas não provocam a ação de dançar, e é uma decisão individual fazêlo ou não ${ }^{18}$. Essa analogia é de alguma forma falsa, pois sugere uma distinção nítida entre sujeito e objeto que não pode ser feita de maneira tão rápida no contexto de um ambiente midiático. De qualquer forma, ambientes têm potencialidades, e deve ficar claro que aquelas do ambiente das mídias digitais são diferentes das do ambiente das mídias eletrônicas. Essa postura parece ser mais convincente e - o que é importante - mais útil na promessa de gerar insights ricos e complexos em relação às transformações tecnológicas, mais do que oferecer frases simplistas e reducionistas que funcionam em adesivos de carro. 
Da mesma forma que ocorre com o rádio, propostas essencialistas e totalizantes são também frequentemente atribuídas às mídias digitais. Diz-se delas que são interativas, descentralizadas, democratizantes, e assim por diante. Mais uma vez, trata-se de aplicações culturais e sociais das tecnologias disponíveis mais do que de características indispensáveis à sua matéria-prima. Talvez ainda mais do que o ambiente tecnológico eletrônico, o contexto das mídias digitais possibilita uma grande amplitude de controle e desígnio sobre o próprio uso das tecnologias por parte daqueles que estão em poder de operar esse controle. Em outras palavras, “o código é a lei” (LESSIG, 2006). Um dos âmbitos de controle mais visíveis e também mais contestados na era digital é aquele do copyright. Ao mesmo tempo, a disputa sobre a propriedade intelectual está longe de ser a única força restritiva sobre a inovação no rádio. Ala-Fossi e Stavitsky (2003) observam, por exemplo, que há muito tempo há uma tradição de suprimir um potencial radical dessa área.

$\mathrm{O}$ inventor americano Edwin $\mathrm{H}$. Armstrong desenvolveu a tecnologia FM nos anos 30, mas seu sistema livre de estática, com qualidade sonora superior à do AM, foi visto como uma ameaça ao já existente mercado das emissoras de rádio comerciais AM, assim como para o monopólio patente da RCA sobre a tecnologia AM e para o programa de distribuição da AT\&T. Mais do que isso, seria necessário que as pessoas comprassem novos receptores enquanto que para a RCA era mais importante que se comprassem aparelhos de televisão. (WINSTON, 1998; DOUGLAS, 1999; WALKER, 2001; HAZLETT, 2001).

E embora possamos argumentar que há, mais do que nunca, oportunidade para inovação - e os responsáveis estão usando todo o poder que têm nas mãos para evitar tais inovações (muitas das quais dependeriam de uma abordagem liberal na observância da estruturação formal do copyright) - , essa restrição à inovação, na verdade, não é nada nova e não devemos nos surpreender quando ela acontece dentro de um ambiente tecnológico em transformação. Mas os responsáveis podem também ser instâncias de inovação 
19. Considerando que se trata da British Broadcasting Corporation e estando sua data de criação localizada nos anos de formação da era eletrônica, é surpreendente que a $\mathrm{BBC}$ tenha uma orientação alocutiva que direcione sua abordagem sobre a inovação midiática. Contudo, há projetos e profissionais relevantes dentro da BBC que oferecem uma visão mais ampla do terreno midiático, que observam o ambiente digital em seus próprios termos e fazem uso das potencialidades inerentes à essa ecologia. e, no Reino Unido, a BBC é um bom exemplo de emissora de grande porte com um mandato para a inovação, embora ela ocorra preferencialmente dentro de um quadro de alocução ${ }^{19}$.

Exemplos de interatividade dentro do contexto do rádio são fáceis de serem encontrados dentro de um tipo de emissão radiofônica de alocução. Embora esses formatos interativos não conformem necessariamente o aspecto geral da programação do rádio em relação a sua forma, estrutura, direção ou intenção, há ao menos uma contribuição sendo feita pelo ouvinte para a comunicação que acontece. Isso significa dizer que, embora possamos questionar até que ponto vai a interatividade, além de contestarmos as condições e contextos em que ela ocorre, o fato de sua existência é inegável.

Uma ampla gama de forças e interesses, ambos aparentemente emancipatórios e restritivos, conformam o ambiente midiático. Dentro desse contexto, os formatos de mídia que emergem o fazem como uma resposta criativa por parte de indivíduos e grupos. A forma final do meio de comunicação é socialmente negociada. No entanto, o que nos interessa aqui para tratar do rádio como prática discursiva é que, embora as potencialidades sejam diferentes de um ambiente midiático a outro, as práticas e culturas da produção, distribuição e consumo radiofônicos não são uniformes - nem nunca foram. As exceções superam a norma nesse caso, e foi sempre assim. Observar a audiência ampliada e sustentada de uma variedade de estações de rádio e de serviços que se assemelham ao rádio cruzando gêneros, em diferentes países, em diferentes horários do dia, em diferentes momentos históricos, traz uma gama fascinante, complexa e diversificada de práticas discursivas. É interessante - e talvez o melhor que possamos esperar como pesquisadores do rádio - ver até que ponto podemos tecer comentários e tirar conclusões sobre o ambiente das mídias digitais a partir do âmbito de práticas similares ao rádio que pareçam relevantes ou que possam ainda gerar ótimos estudos de caso.

Mais do que buscar uma teoria geral do rádio na era digital, nós temos a oportunidade de acionar uma série de teorias especiais que são ao mesmo tempo consistentes entre si, com o ambiente midiático e com outras experiências e observações feitas sobre esse meio de comunicação. Ao fazer isso, podemos chegar a compreender a era digital pelas lentes do rádio mais do que tentar o contrário. 


\section{Referências}

ALA-FOSSI, M; STAVITSKY, A. G. "Understanding IBOC: digital technology for analog economics”. Journal of Radio Studies, v. 10, 2003.

BARHAM, L.; MITCHELL, P. The first Africans: African archaeology from the earliest toolmakers to most recent foragers. Cambridge World Archaeology. Oxford: Oxford University Press, 2008.

BECK, A. Is radio blind or invisible? A call for a wider debate on listening-in [Online]. World Forum for Acoustic Ecology. 1999. Disponível em: <http://wfae.proscenia.net/library/articles/beck_ blindness.pdf>. Accesso em: 16 abr. 2013.

BERRY, R. "Will the iPod kill the radio star? Profiling podcasting as radio". Convergence: The International Journal of Research into New Media Technologies, v. 12, 2006.

BLACK, D. A. "Internet radio: a case study in medium specificity". Media, Culture and Society, v. 23, 2001.

CRISELL, A. Understanding radio. London: Methuen, 1986.

CUTTING, J. E. “Two ecological perspectives: Gibson vs. Shaw and Turvey". The American Journal of Psychology, v. 95, 1982.

DUBBER, A. Radio in the digital age. Cambridge: Polity, 2013.

DUNAWAY, D. K. "Digital radio production: towards an aesthetic". New Media ङ Society, v. 2, 2000.

GIBSON, J. J. "The theory of affordances". In: SHAW, R.; BRANSFORD, J. (Eds.) Perceiving acting and knowing toward an ecological psychology. Series The theory of affordances. Perceiving. Hillsdale, New Jersey: Lawrence Erlbaum, 1977.

GIVEN, J. The death of broadcasting: media's digital future. Sydney: UNSW Press, 1998.

GRÄSLUND, B. The birth of prehistoric chronology: dating methods and dating systems in nineteenth-century Scandinavian archeology. Cambridge: Cambridge University Press, 1987.

HEIZER, R. F. “The background of Thomsen's Three-Age System”. Technology and Culture, v. 3, n. 3, 1962. 
INSKIP, C. “Radio gets personal”. Librany E Information Update, 2009.

LACEY, K. "Ten years of radio studies: the very idea”. The Radio Journal: International Studies in Broadcast and Audio Media, v. 6, 2009.

LAX, S. Digital radio switchover: the UK experience. International Journal of Digital Television, v. 2, 2011.

LESSIG, L. Code: version 2.0. New York: Basic Books, 2006.

LUBBOCK, J. Pre-historic times, as illustrated by ancient remains, and the manners and customs of modern savages. London \& Edinburgh: Williams and Norgate, 1865.

MALINA, J.; VAŠÍCEK, Z. Archaeology yesterday \& today: the development of archaeology in the sciences \& humanities. Cambridge: Cambridge University Press, 1990.

McLUHAN, M. The Gutenberg galaxy: the making of typographic man. Toronto: University of Toronto Press, 1962.

MILLER, P. D. Sound unbound: sampling digital music and culture. Cambridge, Mass: MIT Press, 2008.

MUMFORD, L. Technics and civilisation. New York: Harcourt, Brace \& Company, Inc, 1934.

O'NEILL, B. "Digital radio policy in Canada: from analog replacement to multimedia convergence". Journal of Radio $b$ Audio Media, v. 15, 2008.

RUDIN, R. "The development of DAB digital radio in the UK: the battle for control of a new technology in an old medium". Convergence: The International Journal of Research into New Media Technologies, v. 12, 2006.

SANDERS, J. T. “An ontology of affordances". Online, v. 9, 1997.

SHINGLER, M.; WIERINGA, C. On Air: methods and meanings of radio. London: Arnold, 1998.

*O texto foi fornecido pelo autor em inglês e traduzido por Andrea Limberto.

submetido em: 10 abr. 2013 | aprovado em: 8 maio 2013 